\title{
SELF-CONSISTENT CHLORIDE DIFFUSIVITY UPSCALING IN CEMENT PASTE
}

\author{
N. DAMRONGWIRIYANUPAP ${ }^{*, \dagger}$, S. SCHEINER* ${ }^{*}$, B. PICHLER ${ }^{*}$, AND C. HELLMICH* \\ *Vienna University of Technology \\ Vienna, Austria \\ e-mails: stefan.scheiner@tuwien.ac.at, bernhard.pichler@tuwien.ac.at, christian.hellmich@tuwien.ac.at \\ ${ }^{\dagger}$ University of Phayao \\ Phayao, Thailand \\ e-mail: nattapng_chin@ @otmail.com
}

Key words: Diffusion, Homogenization, Chlorides, Multiscale modeling, Layered water

\begin{abstract}
Chloride ingress into concrete is a major cause for material degradation, such as cracking due to corrosion-induced steel reinforcement swelling. Corresponding transport processes encompass diffusion, convection, and migration, and their mathematical quantification as function of the concrete composition remains an unrevealed enigma. Approaching the problem step by step, we here concentrate on the diffusivity of cement paste, and how it emerges from the microstructural features of the materials, and the chloride diffusivity in the capillary pore spaces. We employ advanced selfconsistent homogenization theory as recently used for permeability upscaling, based on the resolution of the pore space as pore channels being oriented in all space directions. This results in a surprisingly simple analytical (yet implicit) relation between porosity, pore diffusivity and the overall diffusivity of the cement paste. This relation is supported by experiments, and re-confirms the pivotal role that layered water most probably plays in pore diffusivity reduction with respect to that found under the chemical condition of a bulk solution.
\end{abstract}

\section{INTRODUCTION}

The presence of chloride ions in concrete structures is considered a major threat to their durability [1], since chloride ions are known to create a milieu favorable for corrosion of embedded steel bars [2]. In this context, the chloride diffusivity of concrete in particular, and of cementitious materials in general, is a topic of great scientific interest. Here, the key challenge lies in the fact that this diffusivity is not constant, but depends on the composition of the material (governed by the chosen mixture, standardly expressed in terms of the initial waterto-cement mass ratio and the initial aggregateto-cement mass ratio), as well as its maturity (quantified by the so-called degree of hydration).

Numerous experimental campaigns provided valuable insights regarding this compositiondependence, often condensed into (more or less appropriate) simplified empirical relations [3-5]. Importantly, the majority of such diffusion tests have been carried out on cement paste specimens (concrete is regarded as composite consisting of cement paste and aggregates); and in the present paper, we focus on the chloride diffusivity of cement paste as well. Striving for investigation of the microstructural sources driving the overall diffusive properties of cement paste, so-called differential schemes [6], have been utilized, allowing to translate the 
experimental data obtained from cement paste specimens with different mixture into one "universal" chloride diffusivity of the cement paste pore solution, $d_{\text {pore }}=1.07 \times 10^{-10} \mathrm{~m}^{2} / \mathrm{s}$ [7]. Interestingly, this value for $d_{\text {pore }}$ is about 15 times smaller than the chloride diffusivity of a bulk solution, $d_{\text {bulk }}=1.61 \times 10^{-9} \mathrm{~m}^{2} / \mathrm{s}[8]$; and this is probably due to the charged pore surfaces causing water structuring, which, in turn, leads to a reduction of the solution's diffusivity.

Cement paste actually exhibits clearly nonspherical microstructural features, which, however, were not considered by the aformentioned differential schemes. The question arises whether the upscaling-based estimate of the chloride diffusivity of the cement paste pore solution can be improved when considering a more realistic microstructural representation of cement paste. In the present paper, we address this question, and present a homogenization approach considering infinitely many non-spherical phases, for diffusivity upscaling. In particular, we address (i) whether such a more sophisticated and physically profound approach would replicate the experimental data in a more suitable way than the classical differential method-based approach, and (ii) whether and how the corresponding estimate of the chloride diffusivity in the cement paste pore solution changes with respect to its differential methodbased counterpart.

\section{Representative volume element of cement paste}

Following the concept of microporomechanics [9, 10], we consider cement paste as matter filling a representative volume element (RVE) of typically $\ell=1 \mathrm{~mm}$ characteristic length. The heterogeneities found within the microstructure filling the RVE relate to the characteristic length scale of the capillary pores between the hydrates and the yet unhydrated clinker grains. The characteristic length of these pores, $\mathcal{D}$, fulfills the separation-of-scales requirement [10,11] ( $\mathcal{D}$ ranging approximately from 1 to $100 \mu \mathrm{m}$ for early-age cement paste, and from $10 \mathrm{~nm}$ to $1 \mu \mathrm{m}$ for more mature cement paste),
$\mathcal{D} \ll \ell$. This allows for the definition of material properties, such as (chloride) diffusivities, on the level of the entire RVE. On the other hand, the RVE is smaller than a structure or solid (with a characteristic length $\mathcal{L}_{\mathrm{S}}$ ) built up by the material "cement paste", as well as than the characteristic length of RVE-related physical quantities, $\mathcal{L}_{\mathrm{C}}$, here in particular of the "macroscopic" chemical concentration $C$ (i.e. ions per volume in the order of $\ell^{3}$ ), reading as [12], $\mathcal{L}_{\mathrm{C}}=C / \mid$ GRAD $C \mid$, with GRAD as the macroscopic gradient operator. Thus, the second separation-of-scales condition reads as $\ell \ll\left\{\mathcal{L}_{\mathrm{S}}, \mathcal{L}_{\mathrm{C}}\right\}$ [9, 10], allowing for the use of differential calculus throughout the considered solids or structures, i.e. the use of operators such as GRAD.

As the microstructure within the RVE is, as a rule, never known in minute detail, it is represented in the simplest possible (while still sufficiently complex) way, by means of homogeneous subdomains within the RVE, called "material phases". In the present case, these phases are characterized by quantitative properties, namely volume fractions and (chloride) diffusivities: one (spherical) solid phase with volume fraction $\left(1-f_{\text {pore }}\right)$ exhibits negligible diffusivity $\left(\mathbf{d}_{\text {solid }} \approx 0\right)$; while infinitely many, arbitrarily oriented (elongated) cylindrical pore phases fill the remaining volume (with volume fraction $f_{\text {pore }}$ ), and exhibit the (chloride) diffusivity of the pore fluid, $d_{\text {pore }}$, see Figure 1 . At the boundary of the RVE, microscopic chloride concentrations $c(\mathbf{x})$, i.e. amounts of ions per volume in the order of $\mathcal{D}^{3}$, are prescribed; with $\mathrm{x}$ being the location vector inside and at the boundary of the RVE, positioning points at a resolution of $\mathcal{D}$. This way, averaging rules can be derived, for both the concentration gradient,

$$
\operatorname{GRAD} C=\frac{1}{V_{\mathrm{RVE}}} \int_{V_{\mathrm{RVE}}} \operatorname{grad} c(\mathbf{x}) \mathrm{d} V,
$$

and the (ion) flow

$$
\mathbf{J}=\frac{1}{V_{\mathrm{RVE}}} \int_{V_{\mathrm{RVE}}} \mathbf{j}(\mathbf{x}) \mathrm{d} V,
$$




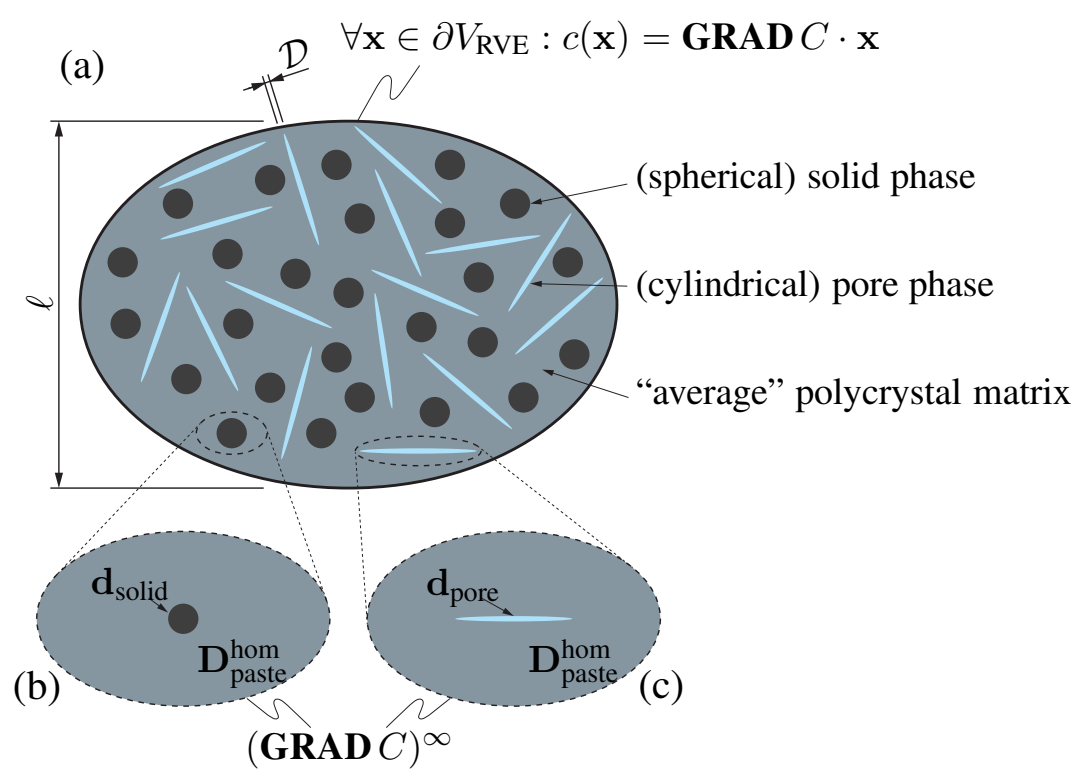

Figure 1: 2D illustration of the 3D micromechanical representation of cement paste: (a) polycrystal-type arrangement of (spherical) solid and (cylindrical) pore phases, with indication of the characteristic lengths of heterogeneities, $\mathcal{D}$, and of the RVE, $\ell, \mathcal{D} \ll \ell$; (b) and (c) show the matrix-inclusion problems used for the derivation of localization tensor $\mathbf{A}_{\text {pore }}$

where $\mathbf{j}(\mathbf{x})$ is the microscopic (ionic) flux, and $\mathbf{J}$ the macroscopic counterpart.

\section{Homogenization of the macroscopic dif- fusion behavior}

Considering a microscopic mass conservation law and a pore space orientation-dependent formulation of Fick's first law of diffusion, allows to derive the following linear downscaling relation for the concentration gradients,

$$
(\operatorname{grad} c)_{\text {pore }}=\mathbf{A}_{\text {pore }}(\vartheta, \varphi) \cdot \mathbf{G R A D} C,
$$

with $\mathbf{A}_{\text {pore }}$ as the second-order "downscaling" or localization tensor related to the concentration gradient of chloride ions encountered in the pore space; such localization tensors have been originally defined for linear elasticity [9, 13], and later also for pressure gradients driving Darcy-type fluid flow [15, 16]. Derivation of $\mathbf{A}_{\text {pore }}$ has been dealt with in great detail in [17], based on Eshelby's famous inhomogeneity problem [18]. Inserting Eq. (3) in the macroscopic, volume-averaged expression for the ionic flux gives access to Fick's first law at the macroscopic observation scale,

$$
\mathbf{J}_{\text {paste }}=-\mathbf{D}_{\text {paste }}^{\text {hom }} \cdot \mathbf{G R A D} C
$$

with the macroscopic diffusion coefficient

$$
\begin{aligned}
\mathbf{D}_{\text {paste }}^{\text {hom }} & =\mathbf{1} D_{\text {paste }}^{\text {hom }}= \\
f_{\text {pore }} & \int_{\varphi=0}^{2 \pi} \int_{\vartheta=0}^{\pi} d_{\text {pore }} \mathbf{A}_{\text {pore }}(\vartheta, \varphi) \frac{\sin \vartheta}{4 \pi} \mathrm{d} \vartheta \mathrm{d} \varphi .
\end{aligned}
$$

Evaluation of $\mathbf{A}_{\text {pore }}$ for the RVE depicted in Figure 1, as demonstrated in [17], eventually yields

$$
\begin{aligned}
D_{\text {paste }}^{\text {hom }}= & \frac{d_{\text {pore }}}{2\left(f_{\text {pore }}+9\right)} \times \\
& {\left[3 \sqrt{33 f_{\text {pore }}^{2}-26 f_{\text {pore }}+9}+\right.} \\
& \left.17 f_{\text {pore }}-9\right] .
\end{aligned}
$$

\section{Re-evaluation of diffusion experiments: access to chloride diffusivity at the cap- illary pore level}

Next, we will check whether many different diffusivity tests at the level of cement paste, with different porosities $f_{\text {pore }}$, deliver, via Eq. (6), the same (or at least) similar values for the pore diffusivity. Such diffusivity tests are usually not directly characterized by the porosity $f_{\text {pore }}$, but rather in terms of the initial water-to-cement mass ratio $(w / c)$, at 
Table 1: Experimentally determined chloride diffusion coefficients in cement paste ( $D_{\text {paste }}^{\text {exp }}$; the corresponding pore space volume fractions $\left(f_{\text {pore }}\right)$ follow from cement paste mixture rules, see [7, 19, 20] for details; pore-scale diffusivity $d_{\text {pore }}$ follows from evaluation of Eq. (6), for the respective data pairs $\left(f_{\text {pore }} ; D_{\text {paste }}^{\exp }\right)$

\begin{tabular}{|c|c|c|c|c|c|}
\hline reference & short name & $\begin{array}{l}w / c \\
{[-]}\end{array}$ & $\begin{array}{l}f_{\text {pore }} \\
{[-]}\end{array}$ & $\begin{array}{c}D_{\text {paste }}^{\exp } \\
{\left[10^{-12} \mathrm{~m}^{2} / \mathrm{s}\right]}\end{array}$ & $\begin{array}{c}d_{\text {pore }} \\
{\left[10^{-10} \mathrm{~m}^{2} / \mathrm{s}\right]}\end{array}$ \\
\hline Page et al. (1981) [21] & P81 & $\begin{array}{l}0.40 \\
0.50 \\
0.60\end{array}$ & $\begin{array}{l}0.071 \\
0.162 \\
0.254\end{array}$ & $\begin{array}{c}2.600 \\
4.470 \\
12.350\end{array}$ & $\begin{array}{l}1.451 \\
0.922 \\
1.349\end{array}$ \\
\hline Yu \& Page (1991) [22] & Y91 & $\begin{array}{l}0.35 \\
0.50 \\
0.60\end{array}$ & $\begin{array}{l}0.071 \\
0.162 \\
0.254\end{array}$ & $\begin{array}{l}1.200 \\
5.430 \\
7.300\end{array}$ & $\begin{array}{l}0.670 \\
1.120 \\
0.798\end{array}$ \\
\hline Tang \& Nilson (1992) [23] & T92 & $\begin{array}{l}0.40 \\
0.60 \\
0.80\end{array}$ & $\begin{array}{l}0.071 \\
0.254 \\
0.387\end{array}$ & $\begin{array}{c}2.900 \\
9.400 \\
21.000\end{array}$ & $\begin{array}{l}1.162 \\
1.027 \\
1.130\end{array}$ \\
\hline Hornain et al. (1995) [24] & H95 & 0.55 & 0.210 & 11.250 & 1.621 \\
\hline MacDonald \& Northwood (1995) [25] & M95 & $\begin{array}{l}0.40 \\
0.40 \\
0.40 \\
0.50 \\
0.50 \\
0.50 \\
0.60 \\
0.60 \\
0.60 \\
0.70 \\
0.70 \\
0.70\end{array}$ & $\begin{array}{l}0.071 \\
0.071 \\
0.071 \\
0.162 \\
0.162 \\
0.162 \\
0.254 \\
0.254 \\
0.254 \\
0.327 \\
0.327 \\
0.327\end{array}$ & $\begin{array}{c}2.353 \\
2.549 \\
2.784 \\
6.412 \\
6.745 \\
7.275 \\
12.290 \\
12.570 \\
13.840 \\
18.730 \\
21.570 \\
21.860\end{array}$ & $\begin{array}{l}1.313 \\
1.422 \\
1.554 \\
1.322 \\
1.391 \\
1.500 \\
1.343 \\
1.373 \\
1.512 \\
1.356 \\
1.562 \\
1.583\end{array}$ \\
\hline Ngala et al. (1995) [26] & N95 & $\begin{array}{l}0.40 \\
0.50 \\
0.60 \\
0.70\end{array}$ & $\begin{array}{l}0.071 \\
0.162 \\
0.254 \\
0.327\end{array}$ & $\begin{array}{c}3.950 \\
7.800 \\
12.600 \\
21.460\end{array}$ & $\begin{array}{l}2.204 \\
1.609 \\
1.377 \\
1.554\end{array}$ \\
\hline Ngala et al. (1997) [27] & N97 & $\begin{array}{l}0.40 \\
0.50 \\
0.60 \\
0.70\end{array}$ & $\begin{array}{l}0.071 \\
0.162 \\
0.254 \\
0.327\end{array}$ & $\begin{array}{c}4.280 \\
8.430 \\
12.300 \\
21.380\end{array}$ & $\begin{array}{l}2.388 \\
1.739 \\
1.344 \\
1.548\end{array}$ \\
\hline Castellote et al. (2001) [28] & $\mathrm{C} 01$ & 0.40 & 0.071 & 3.646 & 2.035 \\
\hline Caré et al. (2003) [29] & $\mathrm{C} 03$ & 0.45 & 0.108 & 5.650 & 1.953 \\
\hline Huang et al. (2010) [30] & $\mathrm{H} 10$ & $\begin{array}{l}0.40 \\
0.50 \\
0.60\end{array}$ & $\begin{array}{l}0.071 \\
0.162 \\
0.254\end{array}$ & $\begin{array}{c}5.420 \\
8.240 \\
12.000\end{array}$ & $\begin{array}{l}3.025 \\
1.700 \\
1.311\end{array}$ \\
\hline Sun et al. (2011) [31] & S11 & $\begin{array}{l}0.23 \\
0.35 \\
0.53\end{array}$ & $\begin{array}{l}0.071 \\
0.071 \\
0.192\end{array}$ & $\begin{array}{c}1.030 \\
4.120 \\
10.600\end{array}$ & $\begin{array}{l}0.575 \\
2.299 \\
1.741\end{array}$ \\
\hline
\end{tabular}

which the cement paste was produced, see Table 1. Based on the famous Powers-Acker model [19, 20], the water-to-cement ratio can be translated into a corresponding pore volume frac- tion $f_{\text {pore }}$. Eq. (6) allows to find, for each data pair $f_{\text {pore }}$ and $D_{\text {paste }}^{\text {exp }}$, one corresponding value for $d_{\text {pore }}$, see the last column of Table 1, The such obtained pore diffusivity values are indeed 


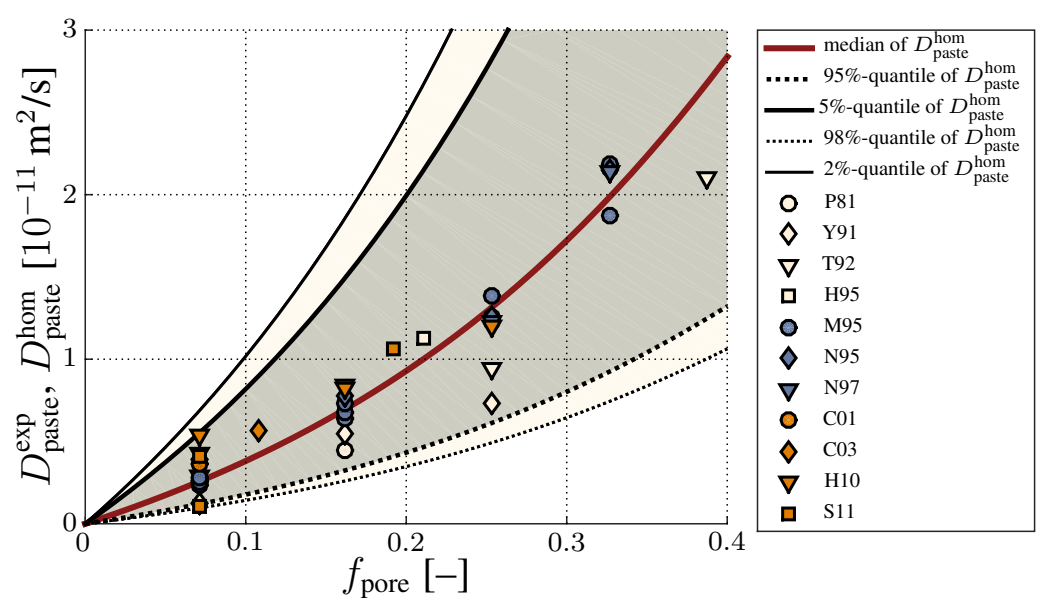

Figure 2: Comparison of model-predicted and experimentally determined chloride diffusion coefficients in cement paste: experimental data, see Table 1, versus model predictions provided by Eq. (6), considering the porosities listed in Table 1 .

well clustered around their mean value $\bar{d}_{\text {pore }}=$ $1.476 \times 10^{-10} \mathrm{~m}^{2} / \mathrm{s}$, with a standard deviation of $5.049 \times 10^{-11} \mathrm{~m}^{2} / \mathrm{s}$. Notably, the value for the pore fluid diffusivity is slightly larger than the one reported in the Introduction of this paper (i.e. $1.07 \times 10^{-10} \mathrm{~m}^{2} / \mathrm{s}$ ), which was determined from a more simplified representation of the microstructure of cement paste. This confirms the earlier posed proposition that the water hosting the ions is actually of layered ("glass-type") structure, and suggests that the more realistic representation of cement paste according to Figure 1 indeed leads to a more precise prediction of the cement paste diffusivity. Namely, the molecular dynamics studies concerning a similar porous geomaterial, i.e. clay, predict a diffusivity decrease from bulk to pore solution by a factor of 7 [32,33]; and our new prediction for the pore solution diffusivity (being by a factor of 10.91 separated from the bulk solution diffusivity) is considerably closer to this factor 7 than the pore solution diffusivity reported in the Introduction of this paper (exhibiting factor 15).

A statistical analysis shows that all but one experimental data point are located within the bounds defined by the $5 \%$-quantile and the $95 \%$-quantile of the $d_{\text {pore }, i}$-population, see Figure 2. The respective outlier, however, is located within the bounds defined by the $2 \%$ quantile and the $98 \%$-quantile of the $d_{\text {pore }, i^{-}}$ population. Furthermore, the trend predicted by the homogenization model fed with the median of the pore diffusivity, $\left(d_{\text {pore }}\right)_{50 \%}=1.438 \times$ $10^{-10} \mathrm{~m}^{2} / \mathrm{s}$, describes the actual, experimentally given porosity-diffusivity trend remarkably well, as underlined by a coefficient of determination of $r^{2}=0.913$.

\section{CONCLUSIONS}

Recent developments in continuum homogenization theories extended to infinitely many material phases related to all orientations in Euclidean space [17] could be successfully applied to diffusivity upscaling. The corresponding results allow for improved representation of water-to-cement ratio- and hydrationdependent diffusivity of cement paste.

\section{ACKNOWLEDGMENTS}

Financial support by the Austrian Federal Ministry of Science and Research (BMWF), through the ASEA UNINET-program, and by the Thailand Research Fund (TRF), via Grant MRG5580222, are gratefully acknowledged.

\section{REFERENCES}

[1] M.G. Stewart and D.V. Rosowsky. Structural safety and serviceability of concrete bridges subject to corrosion. Journal of Infrastructure Systems, 4(4):146-155, 1998.

[2] G.K. Glass and N.R. Buenfeld. The presentation of the chloride threshold level for corrosion of steel in concrete. Corrosion Science, 39(5):1001-1013, 1997. 
[3] C.L. Page and V.T. Ngala. Steadystate diffusion characteristics of cementitious materials. In L.-O. Nilson and J.P. Ollivier, editors, Proceedings of the RILEM International Workshop on 'Chloride penetration into concrete', pages 77 84. RILEM Publishing, Cachan, France, 1997.

[4] B.H. Oh and S.Y. Jang. Prediction of diffusivity of concrete based on simple analytic equations. Cement and Concrete Research, 34(3):463-480, 2004.

[5] G.-W. Sun, W. Sun, Y.-S. Zhang, and Z.-Y. Liu. Relationship between chloride diffusivity and pore structure of hardened cement paste. Journal of Zheijang University - Science A (Applied Physics \& Engineering), 12(5):360-367, 2011.

[6] L. Dormieux and E. Lemarchand. Homogenization approach of advection and diffusion in cracked porous material. Journal of Engineering Mechanics, 127(12):1267-1274, 2001.

[7] P. Pivonka, Ch. Hellmich, and D. Smith. Microscopic effects on chloride diffusivity of cement pastes - a scale-transition analysis. Cement and Concrete Research, 34(12):2251-2260, 2004.

[8] R. Robinson and R. Stokes. Electrolyte Solution. Butterworths, London, UK, 2nd edition, 1959.

[9] A. Zaoui. Continuum micromechanics: survey. Journal of Engineering Mechanics (ASCE), 128(8):808-816, 2002.

[10] L. Dormieux, D. Kondo, and F.-J. Ulm. Microporomechanics. John Wiley \& Sons, 2006.

[11] W.R. Drugan and J.R. Willis. A micromechanics-based nonlocal constitutive equation and estimates of representative volume element size for elastic com- posites. Journal of the Mechanics and Physics of Solids, 44(4):497-524, 1996.

[12] J.-L. Auriault, C. Boutin, and C. Geindreau. Homogenization of Coupled Phenomena in Heterogeneous Media. WileyIste, 2009.

[13] A. Zaoui. Structural Morphology and Constitutive Behavior of Microheterogeneous Materials, chapter 6, pages 291347. Springer-Verlag, Wien New York, 1997. In [14].

[14] P.M. Suquet. Continuum Micromechanics, volume 377 of CISM Courses and Lectures. Springer Verlag, Wien New York, 1997.

[15] L. Dormieux and D. Kondo. Approche micromécanique du couplage perméabilité - endommagement [Micromechanical approach to the approach to the coupling between permeability and damage]. Comptes Rendus Mécanique, 332(2):135140, 2004.

[16] L. Dormieux and D. Kondo. Applied Micromechanics of Porous Media, volume 480 of CISM Courses and Lecture Series, lecture notes Chapter 2 - "Diffusive transport in disordered media. Application to the determination of the tortuosity and the permeability of cracked materials", pages 83-106. Springer-Verlag, Wien New York, 2005.

[17] T. Abdalrahman, S. Scheiner, and C. Hellmich. Is trabecular bone permeability governed by molecular orderinginduced fluid viscosity gain? Arguments from re-evaluation of experimental data in the framework of homogenization theory. Journal of Theoretical Biology, 365:433-444, 2015.

[18] J. Eshelby. The determination of the elastic field of an ellipsoidal inclusion, and related problems. Proceedings of the Royal 
Society London, Series A, 241:376-396, 1957.

[19] P. Acker. Micromechanical analysis of creep and shrinkage mechanisms. In F.J. Ulm, Z.P. Bažant, and F.H. Wittmann, editors, Concreep 6: Creep, Shrinkage and Durability of Concrete and Concrete Structures, Cambridge, USA, pages 1525. Elsevier Science Ltd., 2001.

[20] T.C. Powers and T.L. Brownyard. Studies of the physical properties of hardened Portland cement paste. Research Laboratories of the Portland Cement Association Bulletin, 22:101-992, 1948.

[21] C.L. Page, N.R. Short, and A. Tarras. Diffusion of chloride ions in hardened cement pastes. Cement and Concrete Research, 11(3):395-406, 1981.

[22] S. Yu and C. Page. Diffusion in cementitious materials: 1 . Comparative study of chloride and oxygen diffusion in hydrated cement pastes. Cement and Concrete Research, 21(4):581-588, 1991.

[23] L. Tang and L.-O. Nilson. Rapid determination of chloride diffusivity in concrete by applying an electric field. ACI Materials Journal, 89(1):49-53, 1992.

[24] H. Hornain, J. Marchand, V. Duhot, and M. Moranville-Regourd. Diffusion of chloride ions in limestone filler blended cement pastes and mortars. $\mathrm{Ce}$ ment and Concrete Research, 25(8):16671678, 1995.

[25] K.A. MacDonald and D.O. Northwood. Experimental measurements of chloride ion diffusion rates using a twocompartment diffusion cell: effects of materials and test variables. Cement and Concrete Research, 25(7):1407-1416, 1995.

[26] V.T. Ngala, C.L. Page, L. Parrott, and S. Yu. Diffusion in cementitious materials: 2. Further investigations of chloride and oxygen diffusion in well-cured OPC and OPC/20\% PFA pastes. Cement and Concrete Research, 25(4):819-826, 1995.

[27] V.T. Ngala and C.L. Page. Effects of carbonation on pore structure and diffusional properties of hydrated cement pastes. $\mathrm{Ce}$ ment and Concrete Research, 27(7):9951007, 1997.

[28] M. Castellote, C. Alonso, C. Andrade, G. Chadbourn, and C. Page. Oxygen and chloride diffusion in cement pastes as a validation of chloride diffusion coefficients obtained by steady-state migration tests. Cement and Concrete Research, 31(4):621-625, 2001.

[29] S. Caré. Influence of aggregates on chloride diffusion coefficent into mortar. $\mathrm{Ce}$ ment and Concrete Research, 33(7):10211038, 2003.

[30] X.-F. Huang, J.-J. Zheng, and X.-Z. Zhou. Simple analytical solution for the chloride diffusivity of cement paste. Science and Technology of Overseas Building Materials, 32(2):4-6, 2010.

[31] G. Sun, Y. Zhang, W. Sun, Z. Liu, and C. Wang. Multi-scale prediction of the effective chloride diffusion coefficient of concrete. Construction and Building Materials, 25(10):3820-3831, 2011.

[32] Y. Ichikawa, K. Kawamura, M. Nakano, K. Kitayama, and N. Fujii. Molecular behavior and micro/macro analysis of diffusion problem in bentonite. In $C D-R O M$ Proceedings of the European Congress on Computational Methods in Applied Sciences and Engineering, Barcelona, Spain, 2000.

[33] Y. Ichikawa, K. Kawamura, N. Fujii, and T. Nattavut. Molecular dynamics and multiscale homogenization analysis of seepage/diffusion problem in bentonite clay. International Journal for Numerical Methods in Engineering, 54(12):17171749, 2002. 